\title{
Cardiovascular risk factor profile in subjects with familial predisposition to myocardial infarction in Denmark
}

Merete Hippe, Jørgen Vestbo, Anders Munch Bjerg, Knut Borch-Johnsen, Merete Appleyard, Hans Ole Hein, Per Kragh Andersen, Gorm Jensen, Thorkild I A Sørensen

Copenhagen Centre for Prospective Population Studies, Danish Epidemiology Science Centre at the Institute of Preventive Medicine, Copenhagen University Hospital,

DK 1399,

Copenhagen $\mathrm{K}$

Denmark

$M$ Hippe

J Vestbo

A M Bjerg

T I A Sørensen

Copenhagen County Centre of Preventive

Medicine, Medical

Department C,

Glostrup Hospital,

University of

Copenhagen,

Denmark

K Borch-Johnson

Copenhagen City

Heart Study,

Epidemiological

Research Unit,

Department 7121,

Rigshospitalet,

DK-Copenhagen N,

Denmark

M Appleyard

$G$ Jensen

Copenhagen Male Study,

Epidemiological

Research Unit,

Department of

Occupational

Medicine, 7122 ,

Rigshospitalet,

Copenhagen N,

Denmark

H O Hein

Department of

Biostatistics,

University of

Copenhagen and the

Danish Epidemiology

Science Centre,

Statens Seruminstitut,

Copenhagen S,

Denmark

$\mathrm{P}$ K Andersen

Correspondence to: Dr M Hippe.

Accepted for publication October 1996
Abstract

Study objectives-To identify possible modifiable mediators of familial predisposition to myocardial infarction (MI) by assessing the risk factor profile in individuals without $M I$ in relation to parental occurrence of MI.

Design and methods-Cross sectional survey of the general population. The odds of an adverse cardiovascular risk factor profile in subjects reporting parental occurrence of $M I$ versus subjects not reporting parental occurrence were estimated by logistic regression models.

Setting-The Copenhagen Centre for Prospective Population Studies, where subjects investigated in three Danish prospective population studies are integrated.

Participants-Subjects were 9306 females and 11091 males aged 20-75 years with no history of MI. A total of 1370 subjects reported maternal $M I$ and 2583 reported paternal MI.

Main results-Increased systolic and diastolic blood pressure, increased cholesterol level, low ratio between high density lipoprotein (HDL) and total cholesterol (TC), and heavy smoking, were more frequent in subjects with parental occurrence of $M I$ than in controls irrespective of sex and age of the subjects. Maternal MI was more predictive for increased cholesterol and decreased HDL/ TC ratio than paternal MI, and the risk of an increased cholesterol level was higher in subjects aged 20-39 years than in older subjects. No differences in body mass index, triglycerides, and physical inactivity were observed.

Conclusions-Subjects free of previous MI who reported a parental occurrence of $M I$ had an adverse cardiovascular risk factor profile regarding systolic and diastolic blood pressure, total cholesterol, the ratio between HDL and total cholesterol, and smoking. Thus, these modifiable risk factors may be mediators of the familial predisposition to $M I$.

\section{( $\mathcal{F}$ Epidemiol Community Health 1997;51:266-271)}

Premature death from cardiovascular and cerebrovascular causes has a strong familial background. ${ }^{12}$ How is a familial predisposition to myocardial infarction (MI) expressed in the individual subject?

A number of studies have found parental history of MI to be an independent risk factor of $\mathrm{MI}$ in offspring along with hypertension, raised serum lipids, diabetes, decreased insulin sensitivity, physical inactivity, low social class, and smoking. ${ }^{3-7}$ Several cardiovascular (CVD) risk factors are clustered in families, ${ }^{89}$ and may therefore be mediators of familial predisposition. Part of this may be explained by genetic factors. Most likely, several genes are implicated in the expression of risk factors in offspring. Still, only a few clearly defined genetic traits have been identified-for example, some of the mutated genes associated with hypertension and hypercholesterolaemia. ${ }^{1011}$ Probably, complex combinations of genetic and environmental factors are responsible for the familial clustering. ${ }^{1213}$

Further investigations to clarify the importance of familial predisposition to MI for raised risk factors in offspring are needed. These investigations are of importance for targeting the prevention of disease in high risk individuals with familial predisposition to MI.

The purpose of the present study was to determine whether self reported parental occurrence of $\mathrm{MI}$ predicts an adverse biological and behavioural CVD risk factor profile. Furthermore, the aim was to explore whether the associations depend on the age of the offspring and on whether the MI occurred in the mother, the father, or both.

\section{Methods}

The data originate from The Copenhagen Centre for Prospective Population Studies in which data from three comprehensive Danish prospective population studies have been pooled. These studies are the Copenhagen city heart study, The Copenhagen male study and the Glostrup population studies, including the WHO MONICA studies.

All population studies included assessment of CVD risk factors by a self administered questionnaire and various laboratory tests. The answers to the questionnaires were checked by the staff during the examination. Detailed descriptions of the studies are found elsewhere. ${ }^{14-18}$

The population sample analysed in this paper comprised a total of 20397 subjects aged $20-75$ 
years. The subjects were derived from four cohorts:

- The Copenhagen city heart study, examination in 1981-83, response rate $70 \%$;

- The Copenhagen male study, examination in $1985-86$, response rate $75 \%$;

- The WHO MONICA study I (MONICA I) examination in 1982-83, response rate $79 \%$;

- The WHO MONICA study II (MONICA II), examination in 1986 , response rate $75 \%$.

Subjects with self-reported MI prior to participation in the population studies were excluded $(n=608)$.

Information on the MI status of parents was obtained from the questionnaires. An index case was defined as a participant who answered "yes" to one of two questions: "Did your mother ever suffer from MI (maternal MI)?", or "Did your father ever suffer from MI (paternal $M I)$ ?". The term parental $M I$ was used when at least one parent had suffered from MI (mother and/or father). This type of information is reasonably accurate. ${ }^{19}$ The age at which the parents had their MI was not recorded.

A number of CVD risk factors were investigated as follows: systolic and diastolic blood pressure, total serum cholesterol, HDL cholesterol divided by total cholesterol (HDL TC ratio), triglycerides, body mass index $\left(\mathrm{BMI}=\right.$ weight height $\left.^{2}, \mathrm{~kg} / \mathrm{m}^{2}\right)$, smoking, and physical inactivity.

Subjects with increased risk factor levels were compared with others of the same age, sex, and cohort by standardisation of the risk factors. Thus, increased levels of systolic blood pressure and diastolic blood pressure, cholesterol, triglycerides, and BMI were defined as observed values exceeding $1 \mathrm{SD}$ from the "expected" value - ie, the sex specific, age standardised cohort mean obtained from a linear regression model with age as a continuous variable. The value of the risk factor was if necessary log or $\log$-log-transformed to fit a normal distribution.

Subjects who reported use of antihypertensive medication were included in the group with increased systolic and diastolic blood pressure. For the HDL/TC ratio, ob-

\section{KEY POINTS}

- Parental myocardial infarction (MI) predicts increased blood pressure, increased plasma cholesterol, low ratio between HDL and total cholesterol, and heavy smoking.

- Maternal and paternal MI are equally predictive of increased blood pressure and heavy smoking.

- Maternal MI is more predictive than paternal MI of increased plasma cholesterol and a low HDL and cholesterol ratio.

- Expression of familial predisposition to MI through plasma cholesterol is strongest in younger ages.

- People with a familial predisposition to MI may be a target for modification of risk factors. served values less than -1 SD from the sex specific, age standardised cohort mean were used. Information on smoking and physical activity was obtained from the self administered questionnaire: Heavy smoking was defined as smoking more than $25 \mathrm{~g}$ of tobacco a day and inhaling. One cigarette was taken to correspond to $1 \mathrm{~g}$ tobacco. One cheroot was taken to correspond to $3 \mathrm{~g}$ of tobacco and one cigar to correspond to $5 \mathrm{~g}$ of tobacco. Physical inactivity was defined using a combination of leisure time and work activity as having no physical activity at work or not being employed, together with taking less than 2 hours of physical activity a week during leisure time.

\section{STATISTICAL METHODS}

Logistic regression models ${ }^{20}$ were used to investigate the risk factor profile in index cases versus controls. In each model, the risk factor was included as the dependent variable and paternal MI, maternal MI, or parental MI were included as independent variables.

In order to take into account the increasing prevalence of parental MI in relation to the age of the subjects, the subjects were divided into three age groups: age group I (20-39 years), age group II (40-59 years), and age group III (60-75 years). This allowed us to test for homogeneity of the associations between the risk factors and parental MI over age and thereby to assess for interactions with age. All risk factors were controlled for the influence of age group, sex, and cohort in the multivariate logistic regression model. Furthermore, the risk factors were controlled for possible confounding variables, which were assumed to be associated with the risk factors under study. Blood pressure was controlled for the influence of BMI and smoking, blood lipids were controlled for the influence of BMI, and BMI was controlled for the influence of smoking. Physical inactivity was controlled for the influence of BMI.

We tested for interaction between paternal and maternal $\mathrm{MI}$, for interaction between paternal MI and age groups and between maternal $\mathrm{MI}$ and age groups, and for interaction between paternal MI and sex and between maternal MI and sex. Furthermore, differences between maternal MI and paternal MI were analysed by testing a model with separate parameters for both maternal MI and paternal MI against a model with one parameter for both maternal $\mathrm{MI}$ and paternal MI (parental MI).

Results are given as odds ratio (OR) and $95 \%$ confidence intervals $(95 \% \mathrm{CI})$. The level of significance was set at $5 \%$. P values were two tailed. The statistical analyses were done on a PC using the SPSS for Windows, version 6.1 .

\section{Results}

Altogether 9306 females and 11091 males were included in the analyses. The distribution of males and females and the number of index cases in the four cohorts is given in table 1, and the number of subjects examined in the 
Table 1 Distribution of males and females, index cases and controls included in the study from the four cohorts

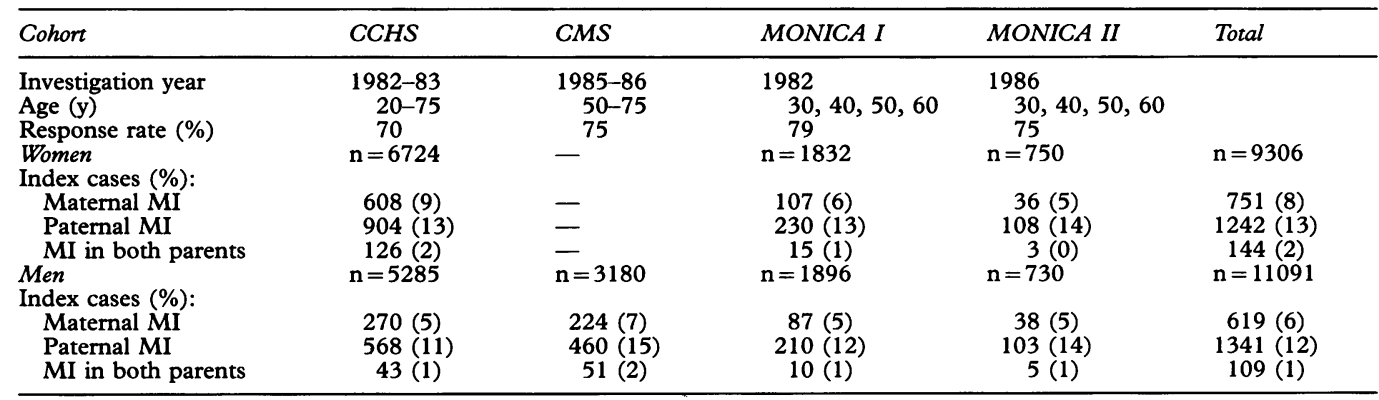

CCHS = The Copenhagen city heart study; CMS = The Copenhagen male study; MONICA I: The WHO-MONICA study I; MONICA II: The WHO-MONICA study II. MI=myocardial infarction.

Table 2 Number of subjects examined in three age groups

\begin{tabular}{lcc}
\hline Age group & Women & Men \\
\hline I (20-39 y) & $\mathrm{n}=1262$ & $\mathrm{n}=1208$ \\
Maternal MI (\%) & $35(3)$ & $28(2)$ \\
Paternal MI (\%) & $115(9)$ & $139(12)$ \\
Both parents MI (\%) & $4(0)$ & $4(0)$ \\
II (40-59 y) & $\mathrm{n}=4644$ & $\mathrm{n}=5057$ \\
Maternal MI (\%) & $424(9)$ & $300(6)$ \\
Paternal MI (\%) & $753(16)$ & $706(14)$ \\
Both parents MI (\%) & $81(2)$ & $55(1)$ \\
III (60-75 y) & $\mathrm{n}=3400$ & $\mathrm{n}=4826$ \\
Maternal MI (\%) & $292(9)$ & $291(6)$ \\
Paternal MI (\%) & $374(11)$ & $496(10)$ \\
Both parents MI (\%) & $59(2)$ & $51(2)$ \\
\hline
\end{tabular}

$\mathrm{MI}=$ myocardial infarction.

Table 3 Odds ratio (OR) of an adverse risk factor profile in subjects with parental myocardial infarction versus controls

\begin{tabular}{llll}
\hline & $\begin{array}{l}\text { OR } \\
\text { (adjusted for age, } \\
\text { sex, and cohort) }\end{array}$ & $\begin{array}{l}\text { OR } \\
\text { (adjusted for age, sex, } \\
\text { cohort and risk factors }\end{array}$ & $(95 \%$ CI) \\
\hline Systolic BP >1 SD & $1.14^{* *}$ & $1.15^{* *}+$ & $(1.06,1.25)$ \\
Diastolic BP >1 SD & $1.13^{* *}$ & $1.14^{* *} \dagger$ & $(1.05,1.24)$ \\
Heavy smoking & $1.17^{*}$ & $1.17^{*}$ & $(1.02,1.34)$ \\
Triglycerides >1 SD & 1.08 & $1.12 \ddagger$ & $(0.96,1.29)$ \\
Physical inactivity & 1.12 & $1.04 \ddagger$ & $(0.92,1.18)$ \\
BMI >1 SD & 0.97 & $0.97 \S$ & $(0.88,1.07)$ \\
\hline
\end{tabular}

† Adjusted for BMI and smoking; $¥$ Adjusted for BMI; $₫$ Adjusted for smoking.

$\mathrm{SD}=$ standard deviation from sex specific, age standardised cohort mean; $\mathrm{BP}=\mathrm{B}$ lood pressure ${ }^{*} \mathrm{p}<0.05 ;{ }^{* *} \mathrm{p}<0.01$. $\mathrm{CI}=$ confidence interval.

three age groups in table 2. As expected, the prevalence of parental MI increased with age, since subjects in the older age groups at the time of examination generally have older parents, who therefore were more likely to have suffered from $\mathrm{MI}$.

A total of $14 \%$ of the participants did not answer the question about paternal MI, and $9 \%$ did not answer the question about maternal MI. In the youngest age group, however, the number of missing values was lower ( $8 \%$ for paternal MI and $6 \%$ for maternal MI). The risk factor profile was unrelated to whether parental occurrence of MI was known. One cohort did not measure triglycerides (CCHS) and the number of missing values for this variable therefore exceeded $40 \%$. Missing values in other variables varied between $0-3 \%$ and were similar in index cases and controls in both genders.

Since cut off points for systolic blood pressure, diastolic blood pressure, cholesterol, triglycerides, BMI, and HDL/TC were chosen to be $1 \mathrm{SD}$, approximately $16 \%$ of the participants had a risk factor level exceeding this (for HDL TC below - 1 SD) from the sex specific, age standardised cohort mean. A total of $6 \%(3 \%$ of females and $9 \%$ of males) were heavy smokers and $8 \%$ ( $11 \%$ of females and $7 \%$ of males) were physically inactive. Nine per cent of both genders were taking antihypertensive drugs.

In tables 3 and 4 the odds ratio with $95 \% \mathrm{CI}$ for an adverse risk factor profile are presented. Both the OR adjusted for age, sex, and cohort and the OR adjusted for the indicated covariates are given.

Increased systolic and diastolic blood pressure, increased cholesterol level, low HDL/TC ratio, and heavy smoking were more frequent in index cases than in controls. No differences were observed in BMI, triglycerides, and physical inactivity (table 3 ). The OR for these risk factors was the same with paternal and maternal MI, and there was no interaction between maternal MI and paternal MI. Furthermore, there was no significant interaction between maternal MI and sex, between paternal MI and sex, between maternal MI and age, or between paternal MI and age. Therefore, the ORs for an adverse risk factor profile for parental MI versus controls in both genders and all age groups are shown in table 3 . The ORs were not substantially altered when the possible con-

Table 4 Odds ratio (OR) of increased cholesterol and decreased HDL/TC ratio. Index cases versus controls

\begin{tabular}{|c|c|c|c|c|c|c|}
\hline & \multicolumn{3}{|c|}{$\begin{array}{l}\text { Paternal MI } \\
(n=2583)\end{array}$} & \multicolumn{3}{|c|}{$\begin{array}{l}\text { Maternal MI } \\
(n=1370)\end{array}$} \\
\hline & ORt & $O R \ddagger$ & $(95 \% C I)$ & OR† & $O R S$ & $(95 \% C I)$ \\
\hline $\begin{array}{l}\text { Cholesterol >1 SD } \\
20-39 \mathrm{y} \\
40-59 \mathrm{y} \\
60-75 \mathrm{y} \\
\text { HDLTC }<1 \mathrm{SD}\end{array}$ & $\begin{array}{l}1.51^{*} \\
1.29^{* *} \\
0.96 \\
1.14^{*}\end{array}$ & $\begin{array}{l}1.52 \\
1.30^{* *} \\
0.96 \\
1.11\end{array}$ & $\begin{array}{l}(1.06,2.19) \\
(1.12,1.51) \\
(0.78,1.19) \\
(0.99,1.26)\end{array}$ & $\begin{array}{l}1.50 \\
1.35^{* *} \\
1.21 \\
1.38^{* *}\end{array}$ & $\begin{array}{l}1.84 \\
1.36^{* *} \\
1.33^{*} \\
1.37^{* *}\end{array}$ & $\begin{array}{l}(0.96,3.51) \\
(1.10,1.66) \\
(1.18,1.60) \\
(1.14,1.55)\end{array}$ \\
\hline
\end{tabular}


founding variables were included in the models.

The associations with cholesterol levels were more complex (table 4). Maternal MI was a stronger predictor for a low HDL/TC ratio than paternal $\mathrm{MI}$ ( 1.37 versus $1.11, \mathrm{p}<0.05)$. The same tendency was seen for increased cholesterol. However, the OR for increased cholesterol differed in the three age groups for paternal MI. The highest risk was found in the youngest age group, with a decreasing tendency towards the older groups. A tendency towards a higher OR in the youngest age group was also seen for maternal MI, although the estimates for the three age groups for maternal MI were not significantly different. There was no significant interaction for either a low HDL TC ratio or an increased cholesterol level between paternal MI and maternal MI, between paternal MI and sex, or between maternal MI and sex. Again the ORs were not substantially altered when the possible confounding variables were included.

\section{Discussion}

In this study of about 20000 men and women aged between 20 and 75 years, increased systolic and diastolic blood pressure, increased cholesterol and a low HDL/TC ratio were significantly more frequent in subjects with parental occurrence of MI (index cases) than in subjects without parental MI. Correspondingly, the percentage of heavy smokers was higher in index cases than controls. We did not find any differences between index cases and controls for BMI, triglycerides, and physical inactivity, which indicates no association with parental occurrence of $\mathrm{MI}$ in these risk factors.

The importance of a family history of MI has been the focal point in many studies. Most of these studies agree that a family history is an individual risk factor for MI. ${ }^{3-52122}$ However, all these studies have included parental occurrence as a covariate together with other cardiovascular risk factors, and therefore have not investigated the influence of parental occurrence on other cardiovascular risk factors.

In order to assess this influence, we have compared subjects with and without parental MI in respect of increased levels of various established cardiovascular risk factors. The method takes into account the fact that several of the risk factors under study may increase by age and, hence, the associations found are not likely to be a consequence of confounding by age.

In our study, the information on familial occurrence of MI was obtained from the questionnaires, which may be a limitation. However, this is the information available in daily clinical work which, together with other risk factors, forms the basis of treatment. Furthermore, a reported family history of $\mathrm{MI}$ is a significant predictor for future disease in this and several other populations. In one of the cohorts used in our study, the relative risk of $\mathrm{MI}$ was 1.4 for subjects who reported parental MI. ${ }^{6}$ An article by Kee et al found a self reported history of MI proved to be almost as predictive for the estimated risk of $\mathrm{MI}$ as a validated family his- tory of MI. Kee et al also found that the positive predictive value of a reported family history was almost equal in MI cases and controls. ${ }^{19}$ In our study, subjects with known MI were excluded, and it is therefore very unlikely that non-random misclassification occurred. The occurrence of random misclassification would only lead to an underestimation of the true OR.

It is a limitation in our study that we do not know the age at which the MI occurred in the parents, and this may tend to dilute the differences between index cases and controls. However, in daily clinical work, information about the parents' age may also be unknown or very inaccurate. Even though the familial component may be more strongly expressed in early MI, where non-familial environmental factors have had limited time to act, genes may also be involved in MI that occurs at a older age. In our analysis, we have to some extent compensated for the lack of an upper age limit, by the age stratification of the index cases and controls, since older subjects when examined will, on average, have older parents who will have had a greater risk of having an MI. Furthermore, we have investigated for age differences in the ORs over strata and found stable effects except for the associations with cholesterol.

It is possible that the number of exclusions due to the non-responders or to inability of participants to determine whether their parents had suffered a MI may have introduced information bias. However, this is not very likely, since information bias requires both a different distribution of parental occurrence of $\mathrm{MI}$ among non-responders and responders and a different distribution of risk factors in nonresponders compared with responders.

\section{BLOOD PRESSURE}

In our study the higher risk of increased systolic and diastolic blood pressure in index cases than controls was the same for maternal and paternal $\mathrm{MI}$, and it persisted after controlling for smoking and BMI. In the coronary artery risk development in young adults study (CARDIA), parental MI was also associated with higher blood pressure levels, although the difference in systolic blood pressure disappeared after adjustment for subscapular skinfold thickness. ${ }^{23}$

\section{CHOLESTEROL AND HDL/TC RATIO}

Our finding of a higher proportion of subjects with increased cholesterol and low HDL/TC ratio in index cases than controls was more pronounced for maternal MI than for paternal MI, which may indicate that the familial component with regard to lipids is more strongly transmitted from the mother than from the father. A possible explanation could be that because of the generally lower incidence of $\mathrm{MI}$ in women, occurrence of maternal MI is more likely than paternal MI to indicate a familial predisposition. In keeping with this, Schildkraut et al found that maternal cardiovascular 
death was a stronger predictor of cardiovascular disease than paternal cardiovascular death. ${ }^{21}$ Other studies have also investigated blood lipids in subjects with parental history of MI..$^{23-26}$ Most of these agree that subjects with a paternal history of MI have higher levels of cholesterol and lower levels of HDL than subjects without parental history of MI. Two of the studies found increased cholesterol only in males. ${ }^{2426}$ A possible explanation could be that these studies have all looked at young individuals, and cholesterol in women does not increase until later in life. ${ }^{14}$

In our study, the expression of familial predisposition through cholesterol level proved to be strongest in the younger age groups. This probably reflects the fact that the parents have suffered from MI at a younger age and that a genetic basis for familial predisposition is expressed most strongly in early MI. Other studies have found that parental occurrence of $\mathrm{MI}$ is more common in young MI patients than in older patients. ${ }^{27}$ The weaker reflection of the familial component in the older age groups may be explained by a growing influence of social and environmental factors with age (eg prolonged effects of lifestyle habits) which may dilute the familial component.

\section{TRIGLYCERIDES}

It is known that the postprandial triglyceride response is prolonged in young male offspring of men with cardiovascular disease, ${ }^{28}$ and correspondingly, the European atherosclerosis research study (EARS) found higher levels of triglycerides in male index cases compared with controls. ${ }^{24} \mathrm{We}$ found a tendency towards higher ORs for increased triglycerides. However, as in the study of De Backer et $a l_{,}{ }^{26}$ the associations were not statistically significant.

\section{SMOKING}

The finding of more heavy smokers in index cases than controls has also been made by De Backer et al, who observed more smokers in both male and female cases with paternal MI. ${ }^{26}$ The risk of cardiovascular morbidity and mortality in smokers with a parental history of MI seems to be even stronger than in smokers without a parental history of $\mathrm{MI} .^{29} \mathrm{It}$ is known that both genetic and environmental factors are implicated in smoking behaviour, ${ }^{30}$ and that subjects smoking as much as 25 cigarettes a day and inhaling are nicotine dependent, which could be an explanation for heavy smoking subjects not quitting smoking in spite of parental MI.

\section{PUBLIC HEALTH IMPLICATIONS}

In consequence of the ORs found in our study, it is very important to realise that subjects apparently free of CVD whose only disadvantage is a parental occurrence of $\mathrm{MI}$, at any age, are $16 \%$ more likely to have increased blood pressure than subjects without a familial predisposition. Furthermore, these subjects are between $30 \%$ and $50 \%$ more likely to have an increased cholesterol level and a decreased HDL/TC ratio.

From a public health point of view, one could assume that the occurrence of an MI in the family would motivate relatives to check their blood pressure and cholesterol, and quit smoking. Our findings elucidate the importance of realising that individuals with family histories of MI form a group in whom selective prevention may be of special importance in the prevention of $\mathrm{MI}$ and associated diseases, particularly because most of the conditions are accessible to treatment.

In conclusion, we found that cardiovascularly healthy subjects with a parental history of MI had an adverse cardiovascular risk factor profile with regard to systolic and diastolic blood pressure, total cholesterol, the ratio between HDL and total cholesterol, and smoking. This study suggests that the familial predisposition to $\mathrm{MI}$ is at least partly mediated through these risk factors. There were no differences between index cases and controls for BMI, triglycerides, and physical inactivity.

The Copenhagen Centre for Prospective Population Studies (steering group: TIA Sørensen, K Borch-Johnsen, G Jensen, HO Hein, N Keiding, J Vestbo) consists of The Copenhagen County Centre of Preventive Medicine ( $T$ Jørgensen, $H$ Ibsen, County Centre of Preventive Medicine (T Jørgensen, H Ibsen, K Borch-Johnsen, P Thorvaldsen, J Clausen), The Copenhagen
Male Study (HO Hein, F Gyntelberg, P Suadicani) and The Male Study (HO Hein, F Gyntelberg, P Suadicani) and The
Copenhagen City Heart Study (G Jensen, P Schnohr, J Nyboe, Copenhagen City Heart Study (G Jensen, P Schnohr, J Ny
M Appleyard, P Lange, M Grønbæk, B Nordestgaard).

M Appleyard, P Lange, M Grønbæk, B Nordestgaard).
Funding: this study was supported by The Danish Heart Funding: this study was supported by The Danish Heart 1661-1). The activities of the Danish Epidemiology Science Centre are supported by a grant from the Danish National Research Foundation.

Conflicts of interest: none.

1 Sørensen TIA, Nielsen G, Andersen PK, Teasdale TW. Genetic and environmental influences on premature death in adult adoptees. $N$ Engl f Med 1988;318:727-32.

2 Marenberg ME, Risch N, Berkman LF, Floderus B, de Faire U. Genetic susceptibility to death from coronary Faire U. Genetic susceptibility to death from coronary heart dise.

3 Barrett Connor E, Khaw K. Family history of heart attack as an independent predictor of death due to cardiovascular disease. Circulation 1984;69:1065-69.

4 Myers RH, Kiely DK, Cupples A, Kannel WB. Parental history is an independent risk factor for coronary artery disease: The Framingham Study. Am Heart $\mathcal{F} 1990 ; 120(4)$ 963-69.

5 Colditz GA, Rimm EB, Giovannucci E, Stampfer MJ Rosner B, Willett WC. A prospective study of parental history of myocardial infarction and coronary artery disease in men. Am $\mathcal{F}$ Cardiol 1991;67:933-38.

6 Nyboe J, Jensen G, Appleyard M, Schnohr P. Risk factors for acute myocardial infarction in Copenhagen. I: Hereditary, educational and socioeconomic factors. Eur Heart $\mathcal{F} 1989$; 10:910-16.

7 Jensen G, Nyboe J, Appleyard M, Schnohr P. Risk factors for acute myocardial infarction in Copenhagen II: Smoking, alcohol intake, physical activity, obesity, oral conalcohol intake, physical activity, obesity, oral con-
traception, diabetes, lipids, and blood pressure. Eur Heart traception, diabetes,

8 Williams RR, Hopkins PN, Hunt SC, et al. Familial dyslipidaemic hypertension and other multiple metabolic syndromes. Ann Med 1992;24:469-75.

9 Hamsten A, de Faire U. Risk factors for coronary artery disease in families of young men with myocardial in farction. Am ₹ Cardiol 1987;59:14-19.

10 Williams RR, Hunt SC, Hopkins PN, Hasstedt SJ, Wu LL, Lalouel JM. Tabulations and expectations regarding the genetics of human hypertension. Kidney Int 1994, 45(Suppl):S-57-S-64.

11 Kontula K, Koivisto UM, Koivisto P, Turtola H. Molecular genetics of familial hypercholesterolaemia: common and rare mutations of the low density lipoprotein receptor gene. Ann Med 1992;24:363-67.

12 ten Kate LP, Boman H, Daiger SP, Motulsky AG. Familial aggregation of coronary heart disease and its relation to
known genetic risk factors. Am $\ngtr$ Cardiol $1982 ; 50: 945-53$.

13 Hunt SC, Hasstedt SJ, Kuida H, Stults BM, Hopkins PN, Williams RR. Genetic heritability and common environmental components of resting and stressed blood pressures, lipids, and body mass index in Utah pedigrees
and twins. Am $\Im$ Epidemiol 1989;129:625-38.

4 Appleyard M. The Copenhagen City Heart Study. Østerbroundersegelsen. A book of tables with data from the 
first examination (1976-78) and a five year follow-up (1981-83). Scand $\mathcal{F}$ Soc Med 1989;170(Suppl): $1-160$.

15 Gyntelberg F. Physical fitness and coronary heart disease in male residents in Copenhagen aged 40-59. Dan Med Bull 1973;20(1):1-4.

16 Hein HO, Suadicani P, Gyntelberg F. Ischaemic heart disease indicence by social class and form of smoking: the Copenhagen male study-17 years' follow-up. F Int Med 1992;231:477-83.

17 Hagerup L, Eriksen M, Schroll M, Hollnagel H, Agner E Larsen $S$. The Glostrup population studies, collection of epidemiologic tables. Scand $\mathcal{F}$ Soc Med 1981;20(Suppl): 5-112.

18 WHO MONICA Project Principal Investigators. The World Health Organization MONICA project (monitoring trends and determinants in cardiovascular disease): A major international collaboration. $\mathcal{f}$ Clin Epidemiol 1988;41(2):10514.

19 Kee F, Tiret L, Robo JY, Nicaud V, McCrum E, Evans A, Cambien F. Reliability of reported family history of myocardial infarction. BMF 1993;307:1528-30.

20 Hosmer DW, Lemeshow S. Applied logistic regression. New York: John Wiley \& Sons, 1989.

21 Schildkraut JM, Myers RH, Cupples LA, Kiely DK, Kannel WB. Coronary risk associated with age and sex of parental heart disease in the Framingham Study. Am $f$ Cardiol heart disease in

22 Hopkins PN, Williams RR, Kuida $\mathrm{H}$, et al. Family history as an independent risk factor for incident coronary artery disease in a high-risk cohort in Utah. Am $\mathcal{f}$ Cardiol 1988; 62:703-7.

23 Burke GL Savage PJ, Sprafka JM, et al. Relation of risk factor levels in young adulthood to parental history of factor levels in young adulthood to parental history of
disease. The CARDIA study. Circulation 1991;84:117687.

24 O'Reilly DSJ, Shepherd J, Tiret L. The distribution of fasting plasma lipid concentrations in the offspring of men with premature coronary heart disease in Europe. The EARS study. Int $\mathcal{F}$ Epidemiol 1994;23:472-81.

25 Ibsen KK, Lous P, Andersen GE. Coronary heart risk factors in 177 children and young adults whose fathers died from ischemic heart disease before age 45. Acta Paediatr Scand 1982;71:609-13.

26 De Backer G, Hulstaert F, De Munck K, Rosseneu M, Van Parijs L, Dramaix $M$. Serum lipids and apoproteins in students whose parents suffered prematurely from a myocardial infarction. Am Heart $\mathcal{f} 1986 ; 112: 478-84$

27 Hoit BD, Gilpin EA, Henning H, Maisel AA, Dittrich H, Carlisle J, et al. Myocardial infarction in young patients: an analysis by age subsets. Circulation 1986;74:712-21.

28 Uiterwaal CS, Grobbee DE, Witteman JC, et al. Postprandial triglyceride response in young adult men and familial risk for coronary atherosclerosis. Ann Intern Med 1994;121: 576-83.

29 Khaw KT, Barrett Connor E. Family history of heart attack: a modifiable risk factor? Circulation 1986;74:239-44.

30 Carmelli D, Swan GE, Robinette D, Fabsitz R. Genetic influence on smoking - a study of male twins. $N$ Engl $\mathfrak{f}$ Med 1992;327:829-33. 